\title{
The Health Beliefs and Perceptions of Adults Living with Diabetes Type 2 in Nigeria
}

\author{
Zuwaira Paula Hashim
}

\section{ABSTRACT}

Introduction: The disease burden of Type 2 diabetes in Nigeria amongst the 54 countries of the African continent. This is so in terms of disease prevalence, morbidity and mortality. Diabetes Type 2 is chronic condition requires regimented management in the form of self-care with implications for health-related behavior. Central to health-related behaviors is the focus on health beliefs and perceptions that underly self-management practices in public health. This systematic review explored health beliefs and perceptions of adults with Type 2 diabetes in Nigeria. The review's objective was to identify challenges to self-management and role of belief systems in such challenges. The study also aimed to draw from the experiences of adults living with Type 2 diabetes in Nigeria to explore the design of future public health interventions.

Method: The following electronic databases- Medline via Web of Science; Cinahl via EBSCO; Web of Science and PubMed were consulted. In addition, Google Scholar, which is an index of other databases was also utilised. The studies were selected based on an inclusion and exclusion criteria. A systematic literature search generated thirteen relevant studies, which were synthesized to address the objectives.

Results: The findings indicated the complex circumstances in which Type 2 diabetes is experienced in the Nigerian population. Themes explored in this review included - lay understandings of type 2 diabetes; traditional healing beliefs and practices; health literacy and self-management; and access to diabetes services, support and counselling.

Conclusion: The findings called for the need to address challenges in terms of engaging beliefs to inform interventions, health education and healthcare delivery systems which impact on health outcomes of diabetics in Nigeria.

Keywords: Type 2 Diabetes, Nigeria, health beliefs, self-management.
Published Online: September 24, 2020

ISSN: $2593-8339$

DOI: 10.24018 /ejmed.2020.2.5.468

Zuwaira Paula Hashim *

The Partnership for Advocacy in Child and Family Health @ Scale (PAS), Nigeria.

(e-mail: pzhashim ${ }^{@}$ yahoo.com)

*Corresponding Author

\section{INTRODUCTION}

Type 2 diabetes mellitus (T2DM) is a serious health and developmental challenge today [1]. Once rare in sub-Saharan Africa, diabetes is becoming a more common health challenge in contemporary times and increasingly so in Nigeria [2]. The health challenge which T2DM represents for Nigeria are issues of significance for the countries of the African Union, in which Nigeria is a leading member. With the largest population and economy in Africa, the burden of T2DM in Nigeria has the potential for undermining the African Union's and the world's achievement of the target of a one-third reduction in premature mortality from noncommunicable diseases by 2030 in Sustainable Development Goal 3 [3]. According to Diabetes UK [4], Nigeria has the highest population of diabetics in Africa as at 2000 with this figure projected to more than double by 2030 . The Diabetes Association of Nigeria (DAN) suggests further that the increasing prevalence of diabetes in Nigeria also accounts for the highest mortality rates, where diabetes-related mortality from inadequate management outweighs that of HIV/AIDs, malaria and cancer in the country [5]. Current estimates state that every eighth sub-Saharan African is a Nigerian and one in every twenty of Nigerian's 76 million adult population is diabetic [6]. These figures are of great concern. This review, therefore, aims to explore the challenges in the management of diabetes type 2 for adults in Nigeria through health beliefs and perceptions and also considers how the experience of living with type 2 diabetes may inform effective public health interventions.

\section{A. Background}

Diabetes mellitus is one of four major non-communicable diseases that constitute an urgent global health problem [7]. The International Diabetes Federation [8] notes that the greatest burden of diabetes is experienced disproportionately in lower and middle-income countries (LMICs). 
Approximately $80 \%$ of global diabetes-related deaths were experienced by LMICs [7]. WHO forecasts an even higher increase in death rates due to suboptimal care provision for diabetes in these countries. This is the case with countries in Africa where reports suggest that in the context of overburdened health infrastructures, T2DM presents an emerging challenge that has attracted global attention [4].

In Nigeria, the prevalence of T2DM is increasing at an unprecedented rate. T2DM in Nigeria is also growing within a conjuncture when three core drivers are also increasing in intensity. These drivers include an ageing Nigerian population; rapid transformation in diets; and increasing urbanization [9], [10]. The IDF's 2013 Global study estimates $5 \%$ of the adult Nigerian population have diabetes [11]. While the most current national survey of non-communicable diseases undertaken in Nigeria, in 1997, estimated a crude prevalence of $2.2 \%$ of diabetes [11]. Therefore, the incidence of T2DM in Nigeria has increased from 1997 to 2013. Significantly, IDF [12] also approximates that a further $70 \%$ - $80 \%$ of the individuals with T2DM are undiagnosed, and indeed, untreated in Nigeria.

This increase in the prevalence of T2DM in Nigeria constitutes a significant health and socioeconomic burden for patients. This is reflected in the rates of premature death and morbidity with implications for the healthcare system and the wider economy [12]. Reports suggest an increased risk of premature death and reduced quality of life of adults with T2DM is occurring in Nigeria as well as the increase in the number of admissions and deaths from hyperglycemia, foot ulceration, chronic kidney disease, cardiovascular complications and blindness [13], [14]. T2DM is also linked to longer hospital stays and is observed in a quarter to a third of all admissions in Nigerian non-surgical medical wards [16]. Specifically, findings from Ogbera's [15] 10-year survey conducted from 1990 - 2000 reported that diabetesrelated admissions and death rates accounted for an aggregate figure of $10 \%$ and $7.6 \%$, respectively. Consequently, life expectancy which is low in Nigeria with women only living to about 54 years and men 52 years, is further reduced by the increased burden of T2DM and diabetes-related complication [16].

Against the background of the poor diabetes outcomes in Nigeria, active self-management is increasingly promoted as part of a concerted effort critical to reducing the burden of T2DM. Self-management, as a form of self-care, is significant for improving diabetes-related symptoms, reducing the risk of complications and ultimately preventing morbidity and mortality. Self-management encompasses medication adherence; self-monitoring blood glucose levels; nutrition therapy and physical activity.

\section{B. Inclusion and exclusion criteria}

In accordance with the Cochrane Reviewers Handbook [17] suggestions for conducting systematic reviews, a protocol was developed where an explicit inclusion and exclusion criteria was defined. The inclusion criteria were primarily set in order to identify and include empirical research and studies focused on the perception and health beliefs of Nigerian adults with T2DM.

The basis of establishing the criteria for inclusion and exclusion is considered in terms of the types of studies and types of participants [18]. The first criteria for the types of studies are research undertaken on Nigeria. As the research question is specifically focused on Nigeria, it is important to make the criteria explicitly clear as a study may focus on a Nigerian population of perhaps, another country. In this systematic review, the scope illustrated that although T2DM is a growing problem, the evidence on Nigeria is limited. Hence the second inclusion criteria are studies with a publication date in the last 15-years. Usually, a maximum time frame of 5 - 10 years is recommended. This is so that the data is current and relevant [19]. However, where there is limited evidence as in the case of Nigeria, as some suggests that the time frame can be extended [20]. The third inclusion criteria on the types of participants are those with T2DM. Lastly, the inclusion criteria also focuses solely on the adult Nigerian population. Adults qualify as individuals over the age of 18 years. Hence the exclusion criteria are research not undertaken on Nigeria; studies published more than 15-years ago; studies on participants with type 1 or gestational diabetes as well as studies, which have reported on individuals under the age of 18 years.

\section{Data extraction}

For this systematic search strategy, the most appropriate databases were selected according to the type of information provided [21]. Specifically, the following electronic databases - Medline via Web of Science, Cinahl via EBSCO, Web of Science and PubMed were chosen. These databases were selected for their health-related evidence. In addition, Google Scholar, which is an index of other databases was also utilised. The use of this wider search engine was deemed necessary due to the limited number of relevant studies.

\section{Critical appraisal}

The use of quality assessment tools is a highly recommended practice [21]. In this systematic review, Guyatt's [22] cross-sectional checklist was utilised. This was selected for the research-specific elements of the checklist and was used in order to assess the quality of each study.

\section{E. Findings}

A review of findings with a thematic analysis identified four distinct themes in Nigerian Diabetics: lay understandings of T2DM; traditional healing beliefs and practices; health literacy and self-management; and access to diabetes services, support and counselling.

\section{F. Lay understandings of T2DM}

All studies of the 13 reviewed presented some evidence of a non-medical belief system that patients had toward their disease and management. This is discussed in terms of misperceptions, and a traditional belief system. In Ogundele's [23] study which surveyed participants belief systems on causes of diabetes the findings showed that all 150 patients in a tertiary healthcare centre, held lay beliefs with a significant percentage believing T2DM was spiritually caused. The study also found that one-third of the participants in this same study who were classed as obese did not believe obesity to be associated with their T2DM. In Adisa's [24] study of 121 ambulatory patients, opinions of the cause of diabetes was also reported. A total of $59.5 \%$ did not know the cause. In comparison, Okolie's [25] study reported $80.2 \%$ of 
participants knew what diabetes was in terms of the relation to levels of blood sugar. Although this was a small sample of 96 and most patients were also literate. Despite their level of literacy, however, when participants were asked what they had believed to be the cause of T2DM, the majority stated that diabetes was caused by poison. This indicated that regardless of their knowledge, the patients had a traditional belief system resulting in misperceptions. Indeed, Jasper [26] discusses lay views of patients about the causes of T2DM in terms of "pervasive fallacies".

Ogundele [23] also noted another lay belief that $13 \%$ of the participants held is that diabetes was curable. Similarly, in Awodele and Osuolale's [27] study some participants believed that T2DM can be cured permanently; only a small percentage believed that diabetes can be controlled using medication and lifestyle modifications.

Adejoh's [28] study which was conducted on 152 outpatients and inpatients in seven hospitals was one of the only studies that utilised the health belief model to assess the perceived susceptibility, perceived severity, perceived benefit and perceived barriers of individuals. Results showed that $42 \%$ of those with a low perception of health belief had poor diabetes management, while $49 \%$ of those with high perception of health belief had good management.

Another study also linked health beliefs to management. In Adisa's [29] survey of 140 patients in an ambulance service, lay beliefs were also demonstrated in terms of patient's beliefs about treatment and use of prescribed medication. Usually, the medication prescribed to diabetics contains hypoglycemic agents necessary for their daily blood glucose regulation over their lifetime. However, the study found that $73.7 \%$ were unaware that they needed to continue their medication throughout their lifetime; $39.5 \%$ were unaware how long they were meant to take it; $14 \%$ had the lay belief that medication should only be taken until the next physician appointment; and $12.3 \%$ had the lay belief that medication should only be taken when they experience symptoms.

\section{G. Traditional healing beliefs and practices}

The significant belief that diabetes can be cured identified in two studies has implications to the search of traditional healing. Adejoh [28] highlighted that having traditional beliefs that diabetes can be cured encouraged diabetics to seek alternative treatments believed to be a cure. The study conducted by Ogundele's [23] revealed that one-third of the participants in this study believed in the use of alternative medicine for treating and curing diabetes $(n=150)$. Alternative medicine included herbal or what is known as traditional medicine as opposed to hypoglycemic agents prescribed in hospital settings.

In Okolie's [25] study of 96 patients in a medical centre, it was reported that more than half of the participants believed that herbs could cure their diabetes. Conversely, a study conducted by Nwankwo [30], where patients attending a government hospital were surveyed on cultural beliefs and practices found different results. This study indicated that 93.6\% were not using alternative medicine and also did not believe that the herbalist could cure them. However, this was only a small sample of 47 . Nevertheless, where this small group of individuals were not currently using traditional medicine, it was found that about half of them reported taking herbal medicine during the course of their disease. It is important to acknowledge that due to the sample size, the study may not be representative but also because the study was undertaken in an urban area rather than rural communities where traditional medicine use is known to be more widespread in Nigeria.

Some studies identified perceived reasons for using traditional medicine instead of prescribed medicines. One study explained this in terms of patients' perception of ineffectiveness of their prescribed medication [31]. While Adisa and Fakeye's [32] study of nonadherence among 153 patients in the outpatient clinics of two teaching hospitals noted that a prevailing behaviour in those who were intentionally nonadherent in their study included the use of herbal remedies in combination with prescribed medication. Other studies explained traditional medicine usage in terms of the cost of prescribed medication. In a study conducted by Awodele and Osuolale [27], it was found that among 150 participants in a general hospital, more than half were of the opinion that T2DM management was not affordable. Notably, in this same study, half of the participants admitted to using herbal medicine either in combination with their medication or exclusively, as participants opted for herbal only medicines.

With regard to traditional practices, one study reported that adults with T2DM in Nigeria applied traditional quasimedical practices. Okolie [25] found that $69.8 \%$ of the participants in their study adopted non-scientific techniques to test their blood glucose level. The patients were reported to have tested their urine for sugar using the tip of their tongue or by urinating on the ground to observe if ants came.

\section{H. Health literacy and self-management}

Health literacy and self-management was prominent in eleven out of thirteen studies, with casual relationships being suggested between health literacy as an independent factor and self-management and adherence as dependent variables. Self-management practices described behaviours such as medication adherence, self-monitoring blood glucose, dietary adjustments and exercise. Most of the studies examined patient's health education of T2DM to explain selfmanagement and adherence. Jasper's [26] study which explored the determinants of diabetes knowledge in 184 diabetics in a community setting, argued for a direct causal relationship between health knowledge and self-management and adherence with positive health outcomes observed. They noted, "the sole greatest panacea and deterrent against diabetes is adequate knowledge of the condition" [26]. Overall, T2DM knowledge in some studies was linked to formal educational levels. Adibe's [33] study of diabetes selfcare knowledge in 314 Nigerian diabetics in four tertiary hospitals identified 19 factors affecting patients' knowledge, in which, educational background was identified as the most influential factor. Jackson's [34] study also showed that selfcare knowledge was closely linked to the level of education of participants and the duration of diabetes.

In a study undertaken by Jackson [34] among 380 participants, $79.5 \%$ of the sample were reported to have a high knowledge level. The same study, however, later found that knowledge of specific self-care practices such as blood glucose monitoring, exercise and hypoglycemic symptoms 
were poor. They explained this in terms of patients lack of familiarity with such practices. Conversely, Adibe's [33] study of a relatively younger and educated sample, predictably, reported patients as knowledgeable. Significantly, Adejoh's [28] study indicated an association between knowledge and management status. The study found that about $60 \%$ of the participants with a low level of diabetes knowledge also had poor management status $(n=152)$. Lack of knowledge, according to Nwankwo [30], meant that diabetics were not able to recognise the inherent danger of not complying as well as recognising the complications of the disease. Indeed, Yusuff's [31] study of 200 patients in tertiary care found only $35 \%$ of patients had knowledge of diabetesrelated complications. Further, the same study assessed patients knowledge of the important features of hypoglycemia which only $53 \%$ were able to identify them.

Seven studies assessed knowledge of key components of diabetes management. These are significant as Yusuff [31] found good blood glucose levels were linked to adherence. Jasper [26] also notes that "diabetes mellitus is a chronic disease, adherence to appropriate self-care practices leads to improved glycaemic control". In Adisa's [29] when patients were assessed on their knowledge of their medication, $12.3 \%$ could not identify the medication that they were taking $(n=140)$. While patients in Adisa's [24] study exhibited a lack of knowledge, once they had remembered to take their medication, $14.9 \%$ of patients doubled the next dose $(n=121)$. In terms of monitoring practices, Adisa's [29] study indicated that only $58.8 \%$ of patients knew their fasting plasma glucose. Among this percentage of patients, $89.6 \%$ were confirmed accurate through medical records while $10.4 \%$ were wrong about their blood glucose level. Adejoh's [28] study, however, found that $36 \%$ did not know what the best method was for testing blood glucose. In Adisa's [24] study, responses of participants also indicated that more than twothirds did not know about self-monitoring (81.1\%). Of the $18.2 \%$ who were aware; they had checked their blood glucose level irregularly using a semi-automatic glucometer.

With regard to other forms of self-management, two-thirds of participants in Adisa's [24] study reported having been recommended dietary restrictions by their doctors. Where it was reported that $95 \%$ complied, this is associated with higher knowledge. Adisa and Fakeye [32], on the other hand, found that commitments to dietary restriction were the least likely for diabetics to comply as they found it challenging. However, this discrepancy may be attributed to the questionable findings of Adisa's [24] study, as self-reports were used in questioning the participants. Patients knowledge of diet in Okolie's [25] study revealed a minority (32.6\%) agreed with a healthy diet of beans, meat, proteinous food, whole grain food, fresh vegetables and fruits $(n=96)$. Similarly, 38\% of participants in Adejoh's [28] study could not identify food which contains carbohydrate and $43 \%$ could not identify food with the highest concentration of fat. Also, in Jasper's [26] study, 88\% did not know that free food meant food that has less than 20 calories per serving. In terms of exercise, in Adisa's [24] study, 82.6\% were recommended aerobic exercise of which the entire $82.6 \%$ reported that they were unaware of the importance of exercise. Adejoh's [28] study also reported $46 \%$ of patients did not know the effects of exercise. Although Awotidebe's [35] survey of 229 patients found half of their participants to have good knowledge of exercise.

On the contrary, other studies explore self-management and adherence in term of attitude and motivation rather than health literacy. Awotidebe's [35] study, focused on exercise as a self-management measure. The study found that $90 \%$ of participants expressed negative attitudes towards exercise. Significantly, this study also found a strong link between the attitudes that participants held, their health education about T2DM and practice of exercise for blood glucose control $(\mathrm{p}=0.804)$. Awotidebe [35] found that despite the participant's knowledge of exercise as a self-care measure, negative attitudes about exercise prevailed. Indeed less than a third of the participants reported engaging in regular exercise.

Adisa and Fakeye [32] also found that non-adherence to prescribed medication was linked to the attitudes of $31.5 \%$ of the participants in their study $(n=153)$. While Jackson [34] found that negative attitudes regarding self-management were associated with knowledge levels $(\mathrm{p}=0.013)$. Adisa [20], on the other hand, linked non-adherence to patients perceived fear of taking too many drugs. Adejoh [28] also focused on motivation rather than diabetes health literacy per se, to explain 'management status'. Adejoh [28] argues that "individuals will not carry out a health-related behaviour unless they have at least a minimal level of health motivation and knowledge, see themselves as vulnerable and the condition as threatening".

\section{Access to diabetes services, support and counselling}

A theme that emerged is patients access to diabetes services, support and counselling in clinical settings and the impact on patients self-management. Adisa and Fakeye [32] recognised that about half of the patients in their study only learnt their blood glucose level when they had visited the hospital and even when they learnt their blood glucose level, more than three-quarters of respondents did not keep a record of the hospital-measured or self-monitored blood glucose level $(\mathrm{n}=153)$. This finding is supported by Nwankwo's [30] study, which found that $80.9 \%$ of their sample had only measured their blood glucose levels at monthly doctors' appointments $(n=47)$. The reasons for this were that $82.7 \%$ stated that they could not afford a glucometer, while $12.8 \%$ did not know what the apparatus was. In this same study, participants responses when surveyed on measures they took when experiencing symptoms of high or low blood glucose indicated that $81.7 \%$ did not know how to check for high or low blood glucose except when they were in the hospital.

Evidenced from Nwankwo's [30] study shows $80.9 \%$ of participants reported receiving health education on diabetic care on every hospital visit while $10.7 \%$ reported that they never received any education. The study further assessed patients that said they had received counselling during every hospital visit. The study found that these participants were in fact poorly educated on self-monitoring blood glucose practices. Okolie's [25] study also found that with regard to the type of information provided by health workers, $39.7 \%$ were informed on the nature, sign and symptoms of diabetes, $35.3 \%$, on diet for diabetes, $14.7 \%$, on self-care and preventing complications while $10.3 \%$ on the significance of exercise. Adisa's [29] study also observed that the approach 
physicians and pharmacists were reported to take with patients was a contributory factor to their non-adherence. Further, Adisa and Fakeye [32] found that participants were substituting their prescribed medication for herbal medicine without disclosing this to their physician.

The study conducted by Awodele and Osuolale [27] was a prospective study in which participants were counselled and educated in order to determine the outcome of the intervention on adherence. The study found that health education and counselling led to improvements in adherence rate, blood glucose level and other health parameters. This study aimed to establish the link between improved health outcomes and education in order to highlight the need for better health promotion in Nigeria. Similarly, in Okolie's [25] study patient at a Federal Medical Center reported being counselled on diabetes self-management with 50 patients learning from laboratory scientists, 11 from doctors, 7 from nurses and 28 reported not being counselled by anyone. The responses of patients in both studies highlight the poor diabetes education in Nigeria and also the need for better support.

\section{DISCUSSION}

Several important findings emerged from the thirteen studies reviewed, of which two broad areas were identified. These two aggregate areas can be located within a wider context of the concepts of self-care agency and health literacy.

Lay understandings of T2DM, revealed important barriers to self-care agency in Nigeria as a result of lay beliefs. Findings pointed to the significance of lay beliefs associated with the causes of diabetes. While the IDF [36] identifies the emerging epidemic of T2DM in Nigeria as a result of genetic and metabolic factors, adult diabetics in Nigeria, hold the belief that T2DM was caused by spirits or poison. Even in instances where patients are classified as obese, these patients did not associate obesity with their diagnosis [23]. Such findings call for close examination of the concept of lay beliefs within a psychosocial context and relate to attribution theory. Attribution theory states that in cases where individuals attribute or identify an external cause for their diagnosis, they often perceive themselves as being unable to change frequently perceived fatalistic outcomes [37].

An additional aspect of lay beliefs found in two studies relates to curability of T2DM. Only a small percentage of patients studied reflected biomedical knowledge of diabetes control through medication and lifestyle modifications. A relevant theory within health psychology related to this belief is Leventhal's [38] common sense self-regulatory model, which focuses on an individual's illness perception and the effect on coping. This model suggests appropriate coping responses are determined by constructs in which an individual's illness perception underpins understandings of their circumstance [38]. Five cognitive dimensions of beliefs are identified in this model, one of which is perceived controllability or curability. This is significant as it suggests a diabetics notion of curability, as opposed to controllability, affects their perception of self-management.

While the findings exemplify lay beliefs, others represented an alternative epistemology or traditional worldview. According to Segall and Fries [39], "the way many people think about health and illness today reflects a complex, holistic health model that is not solely reliant upon the expertise of biomedicine". The focus on the alternative epistemology or traditional perspective is related to the emergence of what is termed the lay expert in health psychology [40]. This concept is significant as it indicates 'belief' and 'knowledge' are not entirely congruent, but rather sharing a degree of overlap [41]. The concept of lay expertise counters the medical dominance of knowledge as it argues 'lay' behaviours are based on rational assimilations of expertise within the wider societal contexts [41]. Indeed, patients develop personal expertise, crucial to their self-care within their social constraints [42]. This is apparent where non-scientific methods of testing blood glucose control were identified in Okolie's [25] study. This involved participants in the study testing their blood sugar level with the tip of their tongue or by urinating on the ground to observe whether ants were attracted. Hence, it is essential to recognise the alternative epistemology as a valid interpretation of maintaining health within the Nigerian diabetics social construct [43]. However, it is important to note that lay schema is a complex and interactive system in which a branch can be both informed and also reflect misperceptions [41].

Traditional healing beliefs and practices were unique to the cultural context of Nigeria. This is related to the role of Ethnobiology and Ethnopharmacology in public health. It is estimated that $80 \%$ of African and Asian countries rely on traditional medicine as their primary therapeutic choice [44]. The uptake of traditional medicine in Nigeria is a common belief-based practice used in the management of chronic conditions [16]. Such beliefs, which originate from culture of the Nigerian social structure, led a significant number of the patients surveyed in six studies to hold views that alternative medicine can treat and indeed, cure T2DM.

Studies explained the use of traditional medicine in Nigerian diabetics in terms of the cost of medication [27]. Similarly, Chinenye's [45] four-year multicenter study noted the cause of poor glycemic control in Nigerian diabetics was principally, financial constraints. Chinenye [45] further insists that "financial constraints is a key factor as most patients have to pay out-of-pocket for their drugs and for blood glucose tests, and at a price which has been found to be much higher than the cost of these drugs in other parts of the world". Chinenye [45] also found the preference for traditional medicine as relating to challenges of accessing healthcare. A study conducted by Rutebemberwa [46], in Eastern Uganda, found diabetics used traditional medicine due to the herbalist promise of a cure and their perceived curability. Indeed, Nwankwo [30] notes that trado-medical practitioners in Nigeria have been known to be featured in Nigerian news media with claims of a discovered remedy for diabetes. Another belief identified as underpinning the use of traditional medicine was participant's perceived inefficiency in their prescribed medication [31].

Although Ethno-pharmacological researchers have identified bioactive principles in some plants, their mechanisms of action remain largely undefined [47]. Furthermore, the implications of traditional medicine usage lie in the undetermined interaction with hypoglycemic agents in the significant numbers who used it alongside their 
prescribed medication as well as, their indiscriminate and irrational use [32]. However, to foster safer use, WHO's Traditional Medicine Strategy advocated for an integration of traditional medicine in healthcare systems and expanding frontiers of research into hypoglycemic properties of plant species [44], [47]. Indeed Nigeria is one of the few countries worldwide, which gives official recognition to traditional medicine in support of the population's traditional belief system [48]. Effective January 2018, the Federal Ministry of Health has a Department of Traditional Medicine [48].

With regard to health literacy and self-management of T2DM through adherence, WHO [49] defines health literacy as "the personal characteristics and social resources needed for individuals and communities to access, understand, appraise and use information and services to make decisions about health". Health literacy is identified as another core area of findings observed in the studies reviewed. The widely recognised Health Belief Model (HBM) provides a strong conceptual framework for understanding health-related behaviour in Nigeria. Within the HBM, knowledge and health literacy, are key factors for patients' determination of seriousness, susceptibility and benefits; while they are less relevant as factors in patients' determination of perceived barriers [46]. Overall, the findings suggested low levels of knowledge about the causes of T2DM, the importance of control and management and related complications in Nigerian diabetics. Additions to the HBM, however, have introduced 'modifying variables' such as education, and 'cues to action' such as media campaigns which enhance knowledge and health literacy [50].

The findings suggested that although adherence for patients compared favourably to the global rate of $36 \%-93 \%$ in diabetic patients, underlying factors differentiated the Nigerian experience [27]. Adherence was explained in terms of attitude and motivation. Two studies identified that in spite of patients knowledge, attitude represented the greatest barrier to adherence and compliance to exercise. The feature of attitude, in essence, challenges the deterministic explanatory power of health literacy in the HBM. However, the HBM expands to incorporate non-rationale variables such as patient motivation, culture and lay beliefs. This is evident in perceived barriers and the term 'self-efficacy'. Bandura [51] defines self-efficacy as the strength of a person's belief in their capabilities. Health literacy also influences self-care behaviours through the mediation of self-efficacy [52].

Fatalism is a key concept often proposed as an explanation for the lack of adherence. Fatalistic attitudes render diabetics helpless to pursue self-management and prolong their quality of life, despite knowing the consequence of their inaction [43]. The findings in Adejoh's [28] study were significant and implied that despite patients' knowledge, fatalistic attitudes hindered self-management. Also in Jasper [26] and Okolie's [25] study, despite participants' knowledge of the benefits of exercise, only a few actually engaged in exercise.

Moreover, findings of the review suggest that Western protocols of inclusive care as medical concordance, in which patients are actively involved in their self-care is not observed in Nigeria. The term, concordance is said to promote a partnership between patients and healthcare professionals through active discussion and decision-making [53]. Findings from the review, however, suggest that most patients did not fully engage in self-management and were instead, reliant on their doctors. Findings of poor health literacy and knowledge, are consistent with an over-reliance on healthcare professionals and with sub-optimal actions to meet the demands of their condition, individually. This is evident from reports of Nwankwo [30] and Adisa and Fakeye [32] studies where the majority of participants lack of knowledge meant they could only check their blood glucose level at hospital appointments.

This feature in which healthcare professionals interacted with patients is explained as a paternalistic approach to care. The over-dependence on healthcare professionals identified represents an important finding as it suggests a power inequity between patient and professionals. Indeed, a critique of the notion of compliance follows this argument. The term has been a source of much debate as it "denotes a passive relationship between patient and health professionals, and therefore an expectation that patients should follow a prescriber's orders without question" [53]. Self-management based on compliance and within paternalistic patientprofessional interaction as found in Nigeria is contrary to an ethos of self-management which is premised on empowering lay people to make their own decisions in managing their health. However, in the Nigerian context, this is less likely to be perceived as paternalistic, considering the limits on patients' self-agency due to knowledge gaps.

Patient's access to diabetes services, support and counselling also affects self-care agency. The concept of selfcare agency is explained through Orem's self-care theory. Self-care agency, according to Orem [54], is defined as an individual's acquired skill or capabilities to engage in selfcare. While the qualified term therapeutic self-care demand refers to the type and amount of self-care required by an external and internal source for patients, to meet the needs of their condition [54]. In triangulating the relationship amongst these concepts, Orem [54] arrives at the conclusion that actions, or therapeutic demand of self-care are not equivalent to an individual's actual ability or agency. Orem's theory suggests ten basic conditioning factors, which include the healthcare systems and resource adequacy and availability can influence self-care agency and lead to poor outcomes [54].

This is consistent with the findings of this review, which suggested that self-management is not only influenced by inherent beliefs and perceptions of adults but also, inadequate access to healthcare services and support. This is significant in suggesting that interventions to improve outcomes in Nigeria which only focus on individual changes may not be sufficient given that many health-related behaviours are influenced by the state of health systems. In two studies, which identified support or available services, patients had better outcomes. Other patients' only access to knowledge was identified in two other studies as doctors rather than specialised programs or educators. This is a cause for concern, which lead six researchers to note the absence of health promotion-led diabetes education programs in Nigeria. These studies also detailed recommendations to public health in Nigeria. 


\section{CONCLUSION}

The findings are of considerable interest to disciplines of Health Psychology, Sociology of illness and Public Health. Overall, the findings support many of the challenges to disease management theorised in literature. However, they also indicated the unique contexts in which adults live with T2DM in Nigeria. Specifically, studies found low health education, health literacy and negative attitudes to self-care to be associated with poor self-management practices and subsequently, health outcomes for T2DM. Underpinning these findings were lay beliefs, traditional healing beliefs as well as misperceptions about the causes of T2DM and knowledge gaps surrounding diabetes treatments and disease monitoring practices. In the absence of self-care directed management practices, adult Nigerians with T2DM relied, extensively, on facility-based healthcare professionals and services in a suboptimal healthcare system. The review, therefore, raised the implications of poor self-management of Nigerian diabetics and poor support of the Nigerian health system.

In light of the findings, there must be calls for comprehensive public education program in Nigeria to respond to people's cultural and deep-seated traditional views. Indeed, it is noteworthy, that there is an absence of health promotion-led diabetes education programs in Nigeria. Programmes derived from these policies must recognise and respect the distinct narratives of illness in Nigerian lay epistemology and thereby seek to educate and impart biomedical knowledge as a complementary addition to lay beliefs, perceptions and practices. Relevant models of practice to expand access to services and education in order to empower patients to self-manage. These are crucial areas for reform, which the Nigerian government and health systems must implement, and fund to reduce mortality rates of T2DM in the country. These recommendations also can also serve to reduce the projected growth in Nigeria's population of type 2 diabetics and reduce the disease burden of T2DM on the African continent.

\section{APPENDIX}

TABLE I: CRITICAL APPRAISAL CHECKLIST

\begin{tabular}{|c|c|c|c|c|c|c|c|c|c|}
\hline Study & $\begin{array}{l}\text { Clear } \\
\text { focus }\end{array}$ & $\begin{array}{l}\text { Appropriate } \\
\text { recruitment }\end{array}$ & $\begin{array}{l}\text { Measures to } \\
\text { reduce bias }\end{array}$ & $\begin{array}{c}\text { Appropriate } \\
\text { data collection }\end{array}$ & $\begin{array}{c}\text { Sample size } \\
\text { adequacy }\end{array}$ & $\begin{array}{c}\text { Presentation } \\
\text { of results }\end{array}$ & $\begin{array}{c}\text { Rigour of } \\
\text { analysis }\end{array}$ & $\begin{array}{l}\text { Clarity of } \\
\text { findings }\end{array}$ & $\begin{array}{c}\text { Generalisability } \\
\text { of findings }\end{array}$ \\
\hline Yusuff et al 2008 & $\mathbf{X}$ & & $\mathbf{N}$ & $\mathbf{X}$ & & $\mathbf{X}$ & $\mathbf{X}$ & $\mathbf{X}$ & $\mathbf{X}$ \\
\hline Ogundele et al 2016 & $\mathbf{X}$ & $\mathbf{X}$ & & $\mathbf{X}$ & $\mathbf{X}$ & $\mathbf{X}$ & & $\mathbf{X}$ & $\mathbf{X}$ \\
\hline Jackson et al 2014 & $\mathbf{X}$ & $\mathbf{X}$ & & $\mathbf{X}$ & $\mathbf{X}$ & $\mathbf{X}$ & $\mathbf{X}$ & $\mathbf{X}$ & $\mathbf{X}$ \\
\hline Adisa et al 2011 & $\mathbf{X}$ & & $\mathbf{X}$ & $\mathbf{X}$ & $\mathbf{X}$ & $\mathbf{X}$ & $\mathbf{X}$ & $\mathbf{X}$ & \\
\hline Adisa et al 2009 & $\mathbf{X}$ & & $\mathbf{X}$ & $\mathbf{X}$ & $\mathbf{X}$ & $\mathbf{X}$ & $\mathbf{X}$ & $\mathbf{X}$ & \\
\hline Awotidebe et al 2016 & $\mathbf{X}$ & $\mathbf{X}$ & & $\mathbf{X}$ & $\mathbf{X}$ & $\mathbf{X}$ & $\mathbf{X}$ & $\mathbf{X}$ & \\
\hline $\begin{array}{l}\text { Awodele and Osuolale } \\
2015\end{array}$ & $\mathbf{X}$ & & & $\mathbf{X}$ & & $\mathbf{X}$ & $\mathbf{X}$ & $\mathbf{X}$ & \\
\hline $\begin{array}{c}\text { Adisa and Fakeye } \\
2014 \\
\end{array}$ & $\mathbf{X}$ & $\mathbf{X}$ & & $\mathbf{X}$ & & $\mathbf{X}$ & $\mathbf{X}$ & $\mathbf{X}$ & \\
\hline Adejoh 2014 & $\mathbf{X}$ & $\mathbf{X}$ & & $\mathbf{X}$ & & $\mathbf{X}$ & $\mathbf{X}$ & $\mathbf{X}$ & \\
\hline Okolie et al 2009 & $\mathbf{X}$ & & & $\mathbf{X}$ & & $\mathbf{X}$ & $\mathbf{X}$ & $\mathbf{X}$ & \\
\hline Nwankwo et al 2010 & $\mathbf{X}$ & & & $\mathbf{X}$ & & $\mathbf{X}$ & $\mathbf{X}$ & $\mathbf{X}$ & \\
\hline Jasper et al 2014 & $\mathbf{X}$ & $\mathbf{X}$ & & $\mathbf{X}$ & & $\mathbf{X}$ & $\mathbf{X}$ & $\mathbf{X}$ & $\mathbf{X}$ \\
\hline Adibe et al 2009 & $\mathbf{X}$ & $\mathbf{X}$ & $\mathbf{X}$ & $\mathbf{X}$ & & $\mathbf{X}$ & $\mathbf{X}$ & $\mathbf{X}$ & \\
\hline
\end{tabular}

TABLE II: THEME MATRIX

\begin{tabular}{|c|c|c|c|c|}
\hline \multicolumn{5}{|c|}{ Themes } \\
\hline Study & $\begin{array}{c}\text { Lay understanding } \\
\text { of T2DM }\end{array}$ & $\begin{array}{c}\text { Traditional healing } \\
\text { beliefs and practices }\end{array}$ & $\begin{array}{c}\text { Health literacy and } \\
\text { self-management }\end{array}$ & $\begin{array}{c}\text { Access to diabetes services, } \\
\text { support and counselling }\end{array}$ \\
\hline Yusuff et al 2008 & & $\mathbf{X}$ & $\mathbf{X}$ & $\mathbf{X}$ \\
\hline Ogundele et al 2016 & $\mathbf{X}$ & $\mathbf{X}$ & $\mathbf{X}$ & \\
\hline Jackson et al 2014 & & & $\mathbf{X}$ & \\
\hline Adisa et al 2011 & $\mathbf{X}$ & & $\mathbf{X}$ & $\mathbf{X}$ \\
\hline Adisa et al 2009 & $\mathbf{X}$ & & & \\
\hline Awotidebe et al 2016 & & & $\mathbf{X}$ & \\
\hline Awodele and Osuolale 2015 & $\mathbf{X}$ & $\mathbf{X}$ & $\mathbf{X}$ & \\
\hline Adisa and Fakeye 2014 & & $\mathbf{X}$ & & $\mathbf{X}$ \\
\hline Adejoh 2014 & $\mathbf{X}$ & & $\mathbf{X}$ & \\
\hline Okolie et al 2009 & & $\mathbf{X}$ & $\mathbf{X}$ & $\mathbf{X}$ \\
\hline Nwankwo et al 2010 & & $\mathbf{X}$ & $\mathbf{X}$ & \\
\hline Jasper et al 2014 & $\mathbf{X}$ & & $\mathbf{X}$ & \\
\hline Adibe et al 2009 & & & $\mathbf{X}$ & \\
\hline
\end{tabular}




\section{PRISMA flow diagram}

Moher D. Liberati A, Tetzlaff J, Altman DG, The PRISMA Group (2009), Preferered Reporting hlems for Systematic Reviews and Meta-
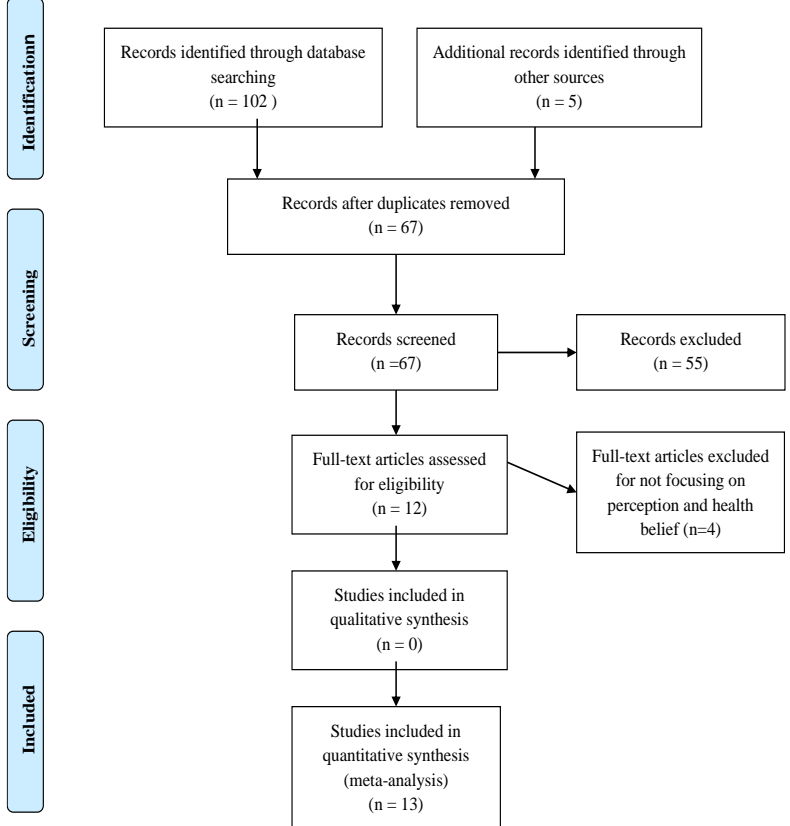

Fig. 1. PRISMA flow diagram [55].

\section{REFERENCES}

[1] URIC. Diabetes: a threat to developing countries. 2013.

[2] Levitt NS. Diabetes in Africa: epidemiology, management and healthcare challenges. Heart. 2008; 1;94(11):1376-82.

[3] Obinna, C. Alliance moves to reduce deaths from Non-communicable Diseases. 2018.

[4] Diabetes UK. Diabetes in Africa. 2018.

[5] Gbenga-Mustapha, O. Diabetes: Nigeria leads in Africa, says WHO. 2013.

[6] Oguejiofor, O., Odenigbo, C., \& Onwukwe, C. Diabetes in Nigeria: Impact, challenges, future directions. Endocrinol Metab Synd. 2014 3(2), 1-9.

[7] World Health Organisation. Global status report on noncommunicable diseases. 2010

[8] International Diabetes Federation. IDF Diabetes Atlas Fifth edition. 2011.

[9] Miranda, J. J., Kinra, S., Casas, J. P., Davey Smith, G., \& Ebrahim, S. Non-communicable diseases in low-and middle-income countries: context, determinants and health policy. Tropical Medicine \& International Health. 2008; 13(10), 1225-1234.

[10] Chinenye, S., Ogu, R., \& Korubo I. Diabetes advocacy and care in Nigeria: A review. Nigerian Health Journal. 2015; 15(4), 145-150.

[11] Adeloye, D., Ige, J. O., Aderemi, A. V., Adeleye, N., Amoo, E. O., Auta, A., \& Oni, G. Estimating the prevalence, hospitalisation and mortality from type 2 diabetes mellitus in Nigeria: a systematic review and meta-analysis. BMJ open. 2017; 7(5), e015424.

[12] Isara, A. R., Omonigho, L., \& Olaoye, D. O. Non-medical management practices for type 2 diabetes in a teaching hospital in southern Nigeria. African Journal of Diabetes Medicine. 2014; 22(2).

[13] Onyekachukwu, O. O. Promoting Diabetes Self Management Education [DSME] through Community Based Care in Nigeria. International Journal of tropical disease \& health. 2016; 19(3), 1-15.

[14] Ogbera, A. O., \& Ekpebegh, C. Diabetes mellitus in Nigeria: The past, present and future. World journal of diabetes. 2014; 5(6), 905.

[15] Ogbera A.O, Ohwovoriole A.E, \& Soyebi O. fatality among diabetic in-patients. J Clin Sci. 2002; 2(18).

[16] Fasanmade, O. A., \& Dagogo-Jack, S. Diabetes care in Nigeria. Annals of global health. 2015; 81(6), 821-829.

[17] Cochrane Collaboration. Cochrane Reviewers' Handbook. 2004.

[18] Bettany-Saltikov, J. How to do a systematic literature review in nursing: a step-by-step guide. McGraw-Hill Education. 2012.

[19] Greenhalgh, T. How to read a paper: The basics of evidence-based medicine. Chichester, West Sussex, UK: Wiley. 2014.

[20] Cronin, P., Ryan, F., \& Coughlan, M. Undertaking a literature review: a step-by-step approach. British journal of nursing. 2008; 17(1), 38-43.
[21] Wakefield, A. Searching and critiquing the research literature. Nursing Standard (Royal College of Nursing (Great Britain). 2014; 28(39), 4957.

[22] Guyatt G. H., Sackett D. L., \& Cook D. J. Users' guides to the medical literature. II. How to use an article about therapy or prevention. JAMA 1993; 270 (21), 2598-2601.

[23] Ogundele, S. O., Dada, A. O., \& Mosuro, O. R. Clinical profile, knowledge, and beliefs about diabetes among patients attending a Tertiary Health Centre in Lagos: A cross sectional survey. Nigerian journal of clinical practice. 2016; 19(4), 508-512.

[24] Adisa, R., Alutundu, M. B., \& Fakeye, T. O. Factors contributing to nonadherence to oral hypoglycemic medications among ambulatory type 2 diabetes patients in Southwestern Nigeria. Pharmacy Practice. 2009; 7(3), 163.

[25] Okolie, V. U., Ehiemere, O. I., Peace, I. N., \& Ngozi, K. I. I Knowledge of diabetes management and control by diabetic patients at Federal Medical Center Umuahia Abia State, Nigeria. International Journal of Medicine and Medical Sciences. 2009; 1(9), 353-358.

[26] Jasper, U. S., Ogundunmade, B. G., Opara, M. C., Akinrolie, O., Pyiki, E. B., \& Umar, A. Determinants of diabetes knowledge in a cohort of Nigerian diabetics. Journal of Diabetes \& Metabolic Disorders. 2014; 13(1), 39.

[27] Awodele, O., \& Osuolale, J. Medication adherence in type 2 diabetes patients: Study of patients in Alimosho General Hospital, Igando, Lagos, Nigeria. African Health Sciences. 2015; 15(2), 513-522.

[28] Adejoh, S. O. Diabetes knowledge, health belief, and diabetes management among the Igala, Nigeria. Sage Open, 4(2). J. U. Duncombe, "Infrared navigation-Part I: An assessment of feasibility," IEEE Trans. Electron Devices. 2014; 11, 34-39.

[29] Adisa, R., Fakeye, T. O., \& Fasanmade, A. Medication adherence among ambulatory patients with type 2 diabetes in a tertiary healthcare setting in southwestern Nigeria. Pharmacy Practice. 2011; 9(2), 72.

[30] Nwankwo, C.H., Nandy, B., \& Nwankwo, B.O. Factors influencing diabetes management outcome among patients attending government health facilities in South East, Nigeria. International Journal of Tropical Medicine. 2010; 5(2), 28-36.

[31] Yusuff, K., Obe, O., \& Joseph, B. Adherence to anti-diabetic drug therapy and self management practices among type-2 diabetics in Nigeria. Pharmacy World \& Science. 2008; 30(6), 876-883.

[32] Adisa, R., \& Fakeye, T. Treatment non-adherence among patients with poorly controlled type 2 diabetes in ambulatory care settings in southwestern Nigeria. African Health Sciences. 2014; 14(1), 1-10.

[33] Adibe, M., Okonta, J. M., Udeogaranya, P., Ayogu, E., Ubaka, C., Isah, A., Amorha, K., Akunne, M. and Onyeanusi, C. Diabetes self-care knowledge among type 2 diabetic outpatients in south-eastern Nigeria. Scientific research and essays. 2009; 9(12), 548-556.

[34] Jackson, I. L., Adibe, M. O., Okonta, M. J., \& Ukwe, C. V. Knowledge of self-care among type 2 diabetes patients in two states of Nigeria. Pharmacy practice. 2014; 12(3).

[35] Awotidebe, T. O., Adedoyin, R. A., Afolabi, M. A., \& Opiyo, R Knowledge, attitude and practice of exercise for plasma blood glucose control among patients with type-2 diabetes. Diabetes \& Metabolic Syndrome: Clinical Research \& Reviews. 2016; 10(2), S1-S6.

[36] International Diabetes Federation. IDF Diabetes Atlas Fifth edition. 2011.

[37] Kelley, H. H., \& Michela, J. L. Attribution theory and research. Annual review of psychology. 1980; 31(1), 457-501.

[38] Larsen, P.D. Chronic illness. Jones \& Bartlett Learning. 2009.

[39] Segall, A., \& Fries, C. J. Pursuing health and wellness: Healthy societies, healthy people. Oxford University Press. 2011.

[40] Storni, C. Patients' lay expertise in chronic self-care: a case study in type 1 diabetes. Health Expectations. 2013; 18(5), 1439-1450.

[41] Bury, M., \& Gabe, J. The sociology of health and illness: A reader (Routledge student readers). London; New York: Routledge. 2004.

[42] Bowling, A. Research methods in health: Investigating health and health services (Fourth ed.). Maidenhead, Berkshire, England: Open University Press. 2014.

[43] Shaw, I., \& Kauppinen-Toropainen, K. Constructions of health and illness: European perspectives. Aldershot: Ashgate. 2004.

[44] Ezuruike, U. F., \& Prieto, J. M. The use of plants in the traditional management of diabetes in Nigeria: pharmacological and toxicological considerations. Journal of Ethnopharmacology. 2014; 155(2), 857-924.

[45] Chinenye, S., Uloko, A. E., Ogbera, A. O., Ofoegbu, E. N., Fasanmade O. A., Fasanmade, A. A., \& Ogbu, O. O. Profile of Nigerians with diabetes mellitus-Diabcare Nigeria study group: Results of a multicenter study. Indian journal of endocrinology and metabolism. 2012; 16(4), 558.

[46] Rutebemberwa, E., Lubega, M., Katureebe, S. K., Oundo, A., Kiweewa, F., \& Mukanga, D. Use of traditional medicine for the treatment of diabetes in Eastern Uganda: a qualitative exploration of 
reasons for choice. BMC International Health and Human Rights. $2013 ; 13(1), 1$

[47] Chikezie, P. C., Ojiako, O. A., \& Nwufo, K. C. Overview of antidiabetic medicinal plants: the Nigerian research experience. J Diabetes Metab. 2015; 6(6), 546

[48] Tyessi, K. Health Minister announces plans to create department of traditional medicine. 2018.

[49] Protheroe, J., Rowlands, G., Bartlam, B., \& Levin-Zamir, D. Health literacy, diabetes prevention, and self-management. Journal of diabetes research. 2017.

[50] Hayden, J. A. Introduction to health behavior theory. Jones \& Bartlett Learning. 2009.

[51] Bandura, A. Self-efficacy: The exercise of control. New York: W.H Freeman. 1997.

[52] Lee, Y. J., Shin, S. J., Wang, R. H., Lin, K. D., Lee, Y. L., \& Wang, Y. H. Pathways of empowerment perceptions, health literacy, selfefficacy, and self-care behaviors to glycemic control in patients with type 2 diabetes mellitus. Patient education and counseling. 2016; 99(2), 287-294.

[53] Mitchell, G. Adherence to medications: Towards a shared understanding. Nurse Prescribing. 2014; 12(11), 564-568.

[54] Orem, D., Taylor, Susan Gebhardt, \& Renpenning, Kathie McLaughlin. Nursing: Concepts of practice (6th ed.). St. Louis, Mo; London: Mosby. 2001.

[55] Moher D, Liberati A, Tetzlaff J, Altman DG, The PRISMA Group (2009). Preferred Reporting Items for Systematic Reviews and MetaAnalyses: The PRISMA Statement. PLoS Med 6(7): e1000097.

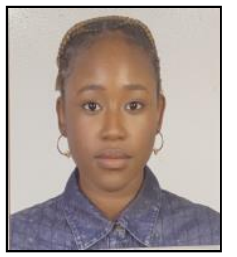

Zuwaira Paula Hashim was born in Kano, Nigeria. She graduated with a first-class Bachelor of Medical Science from the University of Sheffield BMedSci Health and Human Science course, Sheffield, South Yorkshire, England.

Since 2018 she has been engaged on two Bill \& Melinda Gates Foundation (BMGF) funded public health programs in Nigeria. She is a health journalist working in the Premium Times Centre for Investigative Journalism (PTCIJ) BMGF supported program. At PTCIJ she publishes health articles on their online newspaper Premium Times and fact-checking site Dubawa. She is also Public Health Policy Researcher, supporting development Research and Project Centre (dPRC) BMGF funded Partnership for Advocacy in Child and Family Health at Scale project. Public Health Researcher.

Miss Zuwaira P. Hashim has been awarded the Kerry Ann Salt Memorial Award for the highest performance in the University of Sheffield's School of Nursing and Midwifery class of 2018. She was also awarded the Global Engagement award from the University of Sheffield for her work with the Sheffield City Council Public Health Intelligence Team. There she produced and published a Joint Strategic Needs Assessment on Cancer on the Sheffield Gov. site. She also worked on the Sheffield 2016/17 National Child Measurement Programme. 